\title{
Impact of selective and nonselective beta-blockers on the risk of severe exacerbations in patients with COPD
}

This article was published in the following Dove Press journal:

International Journal of COPD

II October 2017

Number of times this article has been viewed

\author{
Yueh Lan Huang' \\ Chih-Cheng Lai ${ }^{2}$ \\ Ya-Hui Wang ${ }^{3}$ \\ Cheng-Yi Wang' \\ Jen-Yu Wang' \\ Hao-Chien Wang ${ }^{4}$ \\ Chong-Jen $\mathrm{Yu}^{4}$ \\ Likwang Chen ${ }^{5}$ \\ On behalf of the Taiwan \\ Clinical Trial Consortium \\ for Respiratory Diseases \\ (TCORE)
}

'Department of Internal Medicine, Cardinal Tien Hospital and School of Medicine,

College of Medicine, Fu Jen Catholic

University, New Taipei City, ${ }^{2}$ Department of

Intensive Care Medicine, Chi Mei Medical

Center, Liouying, Tainan, ${ }^{3}$ Medical Research

Center, Cardinal Tien Hospital and School

of Medicine, College of Medicine, Fu Jen

Catholic University, New Taipei City,

${ }^{4}$ Department of Internal Medicine, National

Taiwan University Hospital and College of

Medicine, National Taiwan University, Taipei,

${ }^{5}$ Institute of Population Health Sciences,

National Health Research Institutes,

Zhunan, Miaoli County, Taiwan

Correspondence: Cheng-Yi Wang

Department of Internal Medicine, Cardinal

Tien Hospital and School of Medicine, College

of Medicine, Fu-Jen Catholic University, 510,

Zhongzheng Road, Xinzhuang District, New

Taipei City 23।48, Taiwan

Tel +88622219339l ext 15433

Fax +886222219065

Email cywang@mospital.com

Hao-Chien Wang

Department of Internal Medicine, National

Taiwan University Hospital, 7 Chung-Shan

South Road, Taipei 1004I, Taiwan

Tel +886223562905

Fax +886223582867

Email haochienwang@gmail.com
Background: There is conflicting information regarding the effects of selective and nonselective beta-blocker treatment in patients with COPD.

Participants and methods: This nested case-control study used the Taiwan National Health Insurance Research Database. We included COPD patients who used inhalation steroid and beta-blockers between 1998 and 2010. From this cohort, there were 16,067 patients with severe exacerbations included in the analysis and 55,970 controls matched on age, sex, COPD diagnosis year, and beta-blockers treatment duration by risk set sampling.

Results: For the selective beta-blocker users, the current users had a lower risk of severe exacerbations than the nonusers (odds ratio [OR], 0.90; 95\% confidence interval [CI], 0.85-0.96). In contrast, for the nonselective beta-blocker users, the current users had a higher risk of severe acute exacerbations than the nonusers (OR, 1.21; 95\% CI, 1.14-1.27). A higher risk of severe exacerbation during increasing mean daily dose or within about the initial 300 days was found in nonselective beta-blockers, but not in selective beta-blockers. One selective beta-blocker, betaxolol, had a significantly lower risk of severe exacerbations (OR, 0.75; 95\% CI, 0.60-0.95). Two nonselective beta-blockers (labetalol and propranolol) were associated with a significantly higher risk of exacerbations (OR, 1.49; 95\% CI, 1.32-1.67 for labetalol; OR, 1.16; 95\% CI, 1.10-1.23 for propranolol).

Conclusion: Selective beta-blockers can be cautiously prescribed for patients with COPD and cardiovascular disease (CVD), however, nonselective beta-blockers should not be prescribed for patients with COPD. Betaxolol may be the preferred choice of suitable selective beta-blocker for patients with COPD, however, labetalol and propranolol should be avoided for patients with COPD.

Keywords: beta-blocker, COPD, selective, nonselective

\section{Introduction}

COPD and cardiovascular disease (CVD) commonly coexist, and tobacco smoking is a major risk factor for both. ${ }^{1-4}$ In addition, the presence of one can affect outcomes of the other. Beta-blockers have been shown to reduce the mortality rate in patients with myocardial infarction, ${ }^{5,6}$ ischemic heart disease, ${ }^{7,8}$ and congestive heart failure, ${ }^{9}$ and they are one of the most prescribed classes of cardiovascular medications. Patients with stage 3 and 4 COPD have a higher risk of severe COPD exacerbations. ${ }^{10}$ However, whether or not beta-blockers should be prescribed for patients with COPD is uncertain, mainly because of concerns that they might induce bronchospasm and worsen lung function. ${ }^{11}$

Despite these concerns, there is emerging evidence that beta-blockers may be beneficial in patients with COPD. ${ }^{12-15}$ One recent meta-analysis enrolling 15 original 
observational cohort studies ${ }^{16}$ showed that beta-blocker treatment could reduce the risk of mortality and exacerbations of COPD. According to the recommendations of the Global Initiative for Chronic Obstructive Lung Disease (GOLD) guideline, treatment with selective beta-blockers is considered to be safe for patients with COPD and coexisting CVD. ${ }^{17}$ Therefore, the primary aim of this study was to investigate the effects of selective and nonselective beta-blocker treatment in patients with COPD on the risk of COPD severe exacerbation.

\section{Methods}

\section{Data source}

The Taiwan National Health Insurance Research Database (NHIRD) contains data from the national insurance program, including outpatient visits, hospital admissions, prescriptions, interventional procedures, and disease profiles of $>99 \%$ of the population in Taiwan (23.12 million in 2009). It is one of the largest and most comprehensive databases in the world, and it has been used extensively in various studies investigating prescriptions, diagnoses, and hospitalizations. In addition, the National Health Research Institutes (NHRI) constructed a longitudinal database based on data from the NHIRD for patients diagnosed with heart or lung disease from 1997 to $2011 .{ }^{18}$ The study protocol was approved by the Institutional Review Board of Cardinal Tien Hospital and School of Medicine, Fu-Jen Catholic University.

\section{Study design}

We used a population-based nested case-control design in this study. All patient records with International Classification of Diseases, Ninth Revision, Clinical Modification (ICD9-CM) codes for COPD (491, 492, and 496) in the NHIRD from 1998 to 2010 were retrieved. Patients were included in this study if they had at least one hospital admission for COPD or three or more outpatient visits for COPD within 365 days. In total, 673,676 patients with COPD were selected (Figure S1). We then selected the patients with lung function tests within 1 year before or after the diagnosis of COPD and excluded those who had no further diagnoses of COPD after the lung function tests. We included the patients who had ever used both inhaled steroids as the severe or very severe group of COPD patients and beta-blockers (either selective or nonselective beta-blockers) who were aged between 40 and 100 years. Nonselective beta-blockers (ATC code C07AA) and selective beta-blockers (ATC code C07AB) dispensed before the index date were identified from NHIRD, and drug exposure was defined by having a drug prescription for at least 7 days. Severe exacerbations of COPD were defined as
COPD-related hospitalizations or emergency visits. Exacerbations that occurred within 14 days were defined as a single event. The included patients were monitored until the first severe COPD exacerbation after entry to the study, death, or until December 31, 2011. All the patients were prospectively followed for at least 1 year after entry to the study.

\section{Patients with severe exacerbations of COPD and the controls}

In total, 27,799 patients with COPD used both inhaled corticosteroids and beta-blockers after the diagnosis of COPD. Of these patients, 16,067 had severe exacerbations and were included in the analysis, along with 55,970 controls matched by age, sex, year of the diagnosis of COPD, and duration of beta-blocker treatment by risk set sampling. The controls were randomly selected from a matched risk set for each case. The risk set consisted of all non-cases in the nested cohort at risk of becoming a case at the time a patient with a severe exacerbation became a case. According to this definition, a person who became a case at a later date was eligible to be a control for another case at a person-time prior to the date of the severe exacerbation event. ${ }^{19}$

\section{Statistical analysis}

Conditional logistic regression analysis was used to estimate the crude and adjusted odds ratios (ORs) and 95\% confidence intervals (CIs) to examine the associations between the use of beta-blockers and the risk of acute exacerbations. We divided the patients into current users (at least one prescription in the 60 days before the event date) and past users (at least one prescription in the year before the event date but no prescription in the 60 days before the event date) and used nonusers as the reference. The occurrence of severe acute exacerbations was calculated according to the mean daily dose and duration (days) of nonselective and selective beta-blockers using conditional logistic regression analysis. Potential dose and duration responses were explored using generalized additive models (GAMs). A two-sided $P$-value of $<0.05$ was considered to be statistically significant.

\section{Results}

Between 1998 and 2010, a total of 673,676 patients were diagnosed with COPD from the NHIRD. We excluded 505,849 patients without pulmonary function tests and 8,678 patients without a diagnosis of COPD after the lung function tests, leaving 156,149 patients with a first diagnosis of COPD from 1998 to 2010. Of these patients, 29,048 had used both inhaled corticosteroids and beta-blockers after the 
diagnosis of COPD. We excluded 1,204 patients aged $<40$ or $>100$ years and 45 patients without complete demographic data. Among the remaining 27,799 patients, 16,067 had severe exacerbations and were enrolled as the case group, and they matched to 55,970 control subjects selected from the cohort of patients with COPD who used inhaled corticosteroids and beta-blockers by risk set sampling (Figure S1).

The case group was older; had more underlying comorbidities, including osteoporosis, diabetes mellitus, cancer, asthma, depression, anxiety, chronic liver disease, renal failure, heart failure, cardiac arrhythmia, acute myocardial infarction, stroke, and ischemic heart disease; and higher Charlson comorbidity index score than the control group (Table 1). The case group had higher rates of exacerbations, hospitalizations for COPD, and emergency department visits. In addition, the case group used more oral steroids and antibiotics than the control group.

Table 2 summarizes the associations between the use of selective and nonselective beta-blockers and the risk of severe

Table I Characteristics of severe AE cases and their matched controls selected from a cohort of patients with COPD

\begin{tabular}{|c|c|c|}
\hline \multirow[t]{2}{*}{ Characteristics } & \multirow{2}{*}{$\begin{array}{l}\text { Controls } \\
n=55,970\end{array}$} & \multirow{2}{*}{$\begin{array}{l}\text { Cases } \\
n=16,067\end{array}$} \\
\hline & & \\
\hline Male, n (\%) & $42,750(76.4)$ & II,978 (74.6) \\
\hline Age, mean $\pm S D$ & $72.12 \pm 8.25$ & $72.50 \pm 9.01$ \\
\hline $\begin{array}{l}\text { Days from COPD diagnosis to drug } \\
\text { date, mean } \pm \text { SD }\end{array}$ & $662.10 \pm 820.68$ & $753.42 \pm 890.29$ \\
\hline \multicolumn{3}{|l|}{ One year before the event date } \\
\hline Exacerbation, ${ }^{a} \mathrm{n}(\%)$ & $21,631(38.6)$ & $8,200(51.0)$ \\
\hline Hospitalization for COPD, n (\%) & $8,050(\mid 4.4)$ & $4,266(26.6)$ \\
\hline Emergency department visits, $\mathrm{n}(\%)$ & $4,27 \mid(7.6)$ & $2,618(16.3)$ \\
\hline Oral steroids, $\mathrm{n}(\%)$ & $9,039(16.1)$ & $4,146(25.8)$ \\
\hline Antibiotics, n (\%) & $5,864(10.5)$ & $2,482(15.4)$ \\
\hline \multicolumn{3}{|l|}{ Comorbidity } \\
\hline Osteoporosis, n (\%) & $4,153(7.4)$ & $\mathrm{I}, 327(8.3)$ \\
\hline DM, n (\%) & $\mid \mathrm{I}, 893(2 \mid .2)$ & $4,001(24.9)$ \\
\hline Cancer, n (\%) & $5,531(9.9)$ & $2,275(14.2)$ \\
\hline Asthma, n (\%) & $21,257(38.0)$ & $8,063(50.2)$ \\
\hline Depression, $\mathrm{n}(\%)$ & $\mathrm{I}, 098(2.0)$ & $350(2.2)$ \\
\hline Anxiety & $12,467(22.3)$ & $3,664(22.8)$ \\
\hline Dyslipidemia, n (\%) & $54(22.0)$ & $3,077(19.2)$ \\
\hline Chronic liver disease, $\mathrm{n}(\%)$ & $7,198(12.9)$ & $2,165(13.5)$ \\
\hline Renal failure, $\mathrm{n}(\%)$ & $5,198(9.3)$ & $2,011(12.5)$ \\
\hline Hypertension, n (\%) & $39,620(70.8)$ & II,299 (70.3) \\
\hline Heart failure, $n(\%)$ & $7,023(12.5)$ & $3,347(20.8)$ \\
\hline Cardiac arrhythmia, n (\%) & $10,298(18.4)$ & $3,557(22.1)$ \\
\hline AMI, n (\%) & $778(1.4)$ & $409(2.5)$ \\
\hline Stroke, n (\%) & $9,137(16.3)$ & $3,114(19.4)$ \\
\hline Ischemic heart disease, $\mathrm{n}(\%)$ & $20,685(37.0)$ & $6,523(40.6)$ \\
\hline $\mathrm{CCl}($ mean $\pm \mathrm{SD})$ & $2.15 \pm 1.65$ & $2.73 \pm 1.98$ \\
\hline
\end{tabular}

Note: axacerbation includes use of antibiotics and oral steroids, emergency visits, and hospitalization for COPD.

Abbreviations: $\mathrm{AE}$, adverse event; $\mathrm{AMI}$, acute mycardial infarction; $\mathrm{CCl}$, Charlson comorbidity index; DM, diabetes mellitus. exacerbations among the patients with COPD. For the selective beta-blocker users, the current users had a lower risk of severe exacerbations than the nonusers (OR, 0.90; 95\% CI, $0.85-0.96)$, but this was not observed with the past users (OR, 0.98 ; 95\% CI, 0.92-1.04). In contrast, for the nonselective beta-blocker users, the current users had a higher risk of severe exacerbations than the nonusers (OR, $1.21 ; 95 \% \mathrm{CI}$, 1.14-1.27); however, again this effect was not observed in the past users (OR, 1.03; 95\% CI, 0.98-1.09).

Table 3 shows the risks of severe exacerbations among the patients with COPD according to the type of beta-blocker used. Among the five selective beta-blockers, only betaxolol had a significantly lower risk of severe exacerbations (OR, 0.75; 95\% CI, 0.60-0.95). For the other four selective beta-blockers (acebutolol, atenolol, bisoprolol, and metoprolol), lower risks of exacerbation were observed (ORs ranging from 0.85 to 0.97 ), although they did not reach statistical significance. In contrast, two nonselective betablockers (labetalol and propranolol) were associated with a significantly higher risk of exacerbations (OR, 1.49; 95\% CI, 1.32-1.67 for labetalol; OR, 1.16; $95 \%$ CI, $1.10-1.23$ for propranolol).

Figure S2 shows the relationships between mean daily dose of nonselective and selective beta-blockers and the occurrence of severe exacerbations. A higher risk of severe exacerbations with a higher mean daily dose was found with the nonselective beta-blockers, but not with the selective beta-blockers. Figure S3 presents the relationships between the duration of nonselective and selective beta-blocker use and the occurrence of severe exacerbation. A higher risk of severe exacerbations was found with nonselective betablockers within approximately the first 300 days, but this was not observed with selective beta-blockers. Figures S2 and S3 show that nonselective beta-blockers caused more severe exacerbations in a dose- and duration-dependent manner.

In subgroup analysis, a higher risk of severe exacerbations was noted in the nonselective beta-blocker users in each subgroup, except for those with atrial fibrillation (Figure 1A). Among the selective beta-blocker users, there was no significant reduced risk of severe exacerbations in any of the subgroups, except for the patients with atrial fibrillation (Figure 1B). The trend was not obvious only in the patients with atrial fibrillation, but this may have been due to the small number of cases.

\section{Discussion}

In this study, the patients with COPD who received selective beta-blockers had a lower risk of severe exacerbations, 
Table 2 Crude and adjusted rate ratios of severe AE associated with current use, dose, and past use of beta-blockers

\begin{tabular}{|c|c|c|c|c|c|c|}
\hline $\begin{array}{l}\text { Use of beta- } \\
\text { blocker }\end{array}$ & Cases & Controls & Crude OR & $95 \% \mathrm{Cl}$ & Adjusted $^{\mathrm{a}}$ OR & $95 \% \mathrm{Cl}$ \\
\hline \multicolumn{7}{|l|}{ Selective beta-blockers } \\
\hline Number of subjects & 16,067 & 55,970 & & & & \\
\hline No use, ${ }^{\mathrm{b}} \mathrm{n}(\%)$ & $12,022(74.8)$ & $39,483(70.5)$ & 1.00 & & 1.00 & Reference \\
\hline Current use, ${ }^{c} \mathrm{n}(\%)$ & $2,212(13.8)$ & $9,860(17.6)$ & 0.76 & $0.72-0.80$ & 0.90 & $0.85-0.96$ \\
\hline Past use, ${ }^{d}$ n (\%) & I,833 (I I.4) & 6,627 (II.8) & 0.95 & $0.90-1.01$ & 0.98 & $0.92-1.04$ \\
\hline \multicolumn{7}{|c|}{ Nonselective beta-blockers } \\
\hline Number of subjects & 16,067 & 55,970 & & & & \\
\hline No use, ${ }^{b} \mathrm{n}(\%)$ & $8,402(52.3)$ & $31,705(56.6)$ & 1.00 & & 1.00 & Reference \\
\hline Current use, ${ }^{c} \mathrm{n}(\%)$ & $4,316(26.9)$ & $12,878(23.0)$ & 1.35 & $1.29-1.42$ & 1.21 & $1.14-1.27$ \\
\hline Past use, ${ }^{d}$ n (\%) & $3,349(20.8)$ & II,387 (20.3) & 1.14 & $1.08-1.20$ & 1.03 & $0.98-1.09$ \\
\hline
\end{tabular}

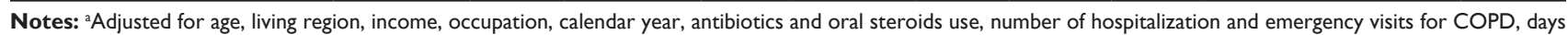
from COPD diagnosis to beta-blockers use, and comorbidities (including osteoporosis, DM, cancer, and asthma). ${ }^{\mathrm{b}} \mathrm{No}$ use in recent year. ${ }^{\mathrm{c} A t}$ least one prescription in the 60 days before the event date. ${ }^{\mathrm{d} A t}$ least one prescription in the year before the event date, but no prescription in the 60 days before the event date.

Abbreviations: $\mathrm{AE}$, adverse event; $\mathrm{OR}$, odds ratio; $\mathrm{Cl}$, confidence interval; $\mathrm{DM}$, diabetes mellitus.

especially the current users. In contrast, the patients with COPD who used nonselective beta-blockers had a higher risk of severe exacerbations in a dose- and duration-dependent manner. Similar trends were also noted in subgroup analysis. Our findings are consistent with previous meta-analyses..$^{20,21}$ $\mathrm{Ni}$ et $\mathrm{al}^{20}$ analyzed five randomized, placebo-controlled, blinded trials and found that the forced expiratory volume in 1 second $\left(\mathrm{FEV}_{1}\right)$ decreased by $0.14 \mathrm{~L}$ in the patients who used nonselective beta-blockers and by $0.03 \mathrm{~L}$ in those who used selective beta-blockers. Moreover, the responsiveness of $\mathrm{FEV}_{1}$ to beta-agonists was reduced by $13.42 \%$ after the use of nonselective beta-blockers, but no significant change was noted after using selective beta-blockers. Similar results were reported in another meta-analysis, ${ }^{21}$ in which selective beta-blockers, used in a single dose or for a longer duration, did not change $\mathrm{FEV}_{1}$ or respiratory symptoms compared to a placebo and had no effect on the $\mathrm{FEV}_{1}$ response to beta2agonists. Therefore, our findings and previous reports suggest that the use of selective beta-blockers does not result in adverse respiratory effects among patients with COPD and that selective beta-blockers can be cautiously prescribed for patients with COPD and CVD. In contrast, nonselective beta-blockers should not be prescribed for patients with COPD due to their negative impact on physiological and clinical conditions.

In this study, betaxolol was the most effective selective beta-blocker in reducing the risk of severe exacerbations in the patients with COPD with the lowest OR of 0.75

Table 3 Risk of severe $A E$ associated with any current use of selective/nonselective beta-blockers in patients with COPD

\begin{tabular}{|c|c|c|c|c|c|c|}
\hline Drug type & Cases & Controls & Crude OR & $95 \% \mathrm{Cl}$ & Adjusted $^{\mathrm{a}}$ OR & $95 \% \mathrm{Cl}$ \\
\hline \multicolumn{7}{|l|}{ Selective } \\
\hline Acebutolol & 150 & 804 & 0.71 & $0.59-0.84$ & 0.85 & $0.71-1.02$ \\
\hline Atenolol & I,568 & 6,804 & 0.82 & $0.77-0.87$ & 0.97 & $0.91-1.03$ \\
\hline Betaxolol & 92 & 542 & 0.63 & $0.50-0.78$ & 0.75 & $0.60-0.95$ \\
\hline Bisoprolol & 195 & 768 & 0.77 & $0.66-0.91$ & 0.85 & $0.71-1.01$ \\
\hline Metoprolol & 183 & 795 & 0.81 & $0.69-0.96$ & 0.88 & $0.74-1.04$ \\
\hline \multicolumn{7}{|l|}{ Nonselective } \\
\hline Alprenolol & 13 & 66 & 0.69 & $0.38-1.27$ & 0.70 & $0.38-1.30$ \\
\hline Carteolol & 28 & 100 & 1.05 & $0.69-1.60$ & 1.02 & $0.65-1.61$ \\
\hline Carvedilol & 753 & 2,397 & 1.08 & $0.99-1.17$ & 0.97 & $0.88-1.06$ \\
\hline Labetalol & 525 & 1,167 & 1.62 & $1.46-1.81$ & 1.49 & $1.32-1.67$ \\
\hline Nadolol & 45 & 149 & 1.12 & $0.80-1.57$ & 1.17 & $0.82-1.66$ \\
\hline Pindolol & 5 & 42 & $0.4 I$ & $0.16-1.05$ & 0.39 & $0.15-1.01$ \\
\hline Propranolol & 3,031 & $9,|3|$ & 1.24 & $1 . \mid 8-1.31$ & 1.16 & $1.10-1.23$ \\
\hline Sotalol & 4 & 30 & 0.49 & $0.17-1.40$ & 0.57 & $0.19-1.71$ \\
\hline
\end{tabular}

Note: ${ }^{a}$ Adjusted for age, living region, income, occupation, calendar year, antibiotics and oral steroids use, number of hospitalization and emergency visits for COPD, days from COPD diagnosis to beta-blockers use, and comorbidities.

Abbreviations: $\mathrm{AE}$, adverse event; $\mathrm{OR}$, odds ratio; $\mathrm{Cl}$, confidence interval. 
A

B

Ischemic heart disease
Yes
No
Heart failure
Yes
No
Atrial fibrillation
Yes
No
Hypertension
Yes
No

Nonselective beta-blockers

Non current users

(events/persons)

$3,850 / 17,169$

$7,901 / 37,674$

$1,748 / 6,340$

$10,003 / 48,503$

$416 / 1,465$

$11,335 / 53,378$

$7,390 / 34,591$

$4,361 / 20,252$
$2,650 / 10,632$

$1,666 / 6,562$

$\begin{aligned} & \text { Current users } \\ & \text { (events/persons) }\end{aligned}$
$808 / 4,064$
$1,404 / 8,008$
$334 / 1,317$
$1,878 / 10,755$
$81 / 306$
$2,131 / 11,766$
$1,716 / 9,591$
$496 / 2,481$

Selective beta-blockers

Non current users

(events/persons)

$4,808 / 19,871$

$9,047 / 40,094$

$2,358 / 7,903$

$11,497 / 52,062$

$614 / 2,021$

$13,241 / 57,944$

$8,324 / 35,632$

$5,531 / 24,333$

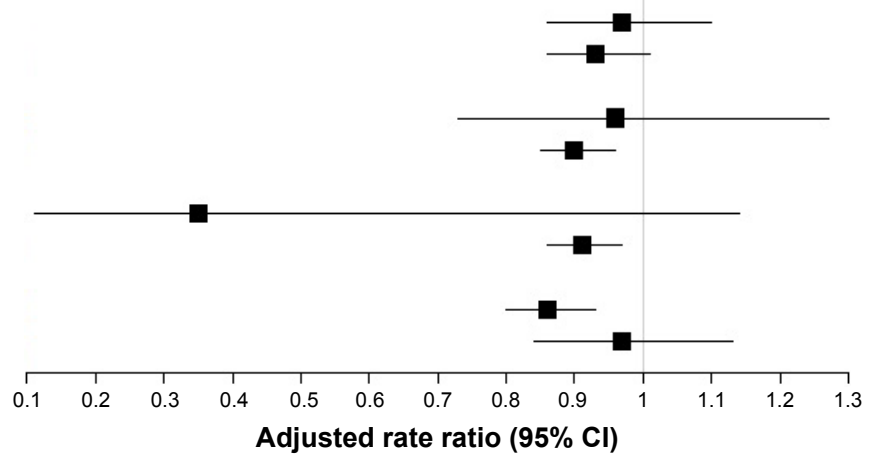

Figure I Subgroup analysis of COPD severe exacerbation among (A) nonselective and (B) selective beta-blockers.

(95\% CI, 0.60-0.95). This could be explained by previous reports, ${ }^{22,23}$ in that betaxolol is considered to be highly cardioselective and less likely than other beta1-selective blockers to cause pulmonary adverse effects. In a physiological study, ${ }^{23}$ no significant changes were noted in terms of forced vital capacity (FVC) or $\mathrm{FEV}_{1}$, and the $\mathrm{FEV}_{1} / \mathrm{FVC}$ ratio was $3.19 \pm 0.91 \mathrm{~L}$ compared to $3.23 \pm 0.89 \mathrm{~L}$ after 2 weeks of betaxolol therapy in patients with COPD. This suggests that betaxolol may be the most suitable selective beta-blocker for patients with COPD. However, further large-scale studies are warranted to confirm this hypothesis.

For nonselective blockers, we found that labetalol and propranolol were significantly associated with a higher risk of severe exacerbations in the patients with COPD. This could be because labetalol can significantly reduce both $\mathrm{FEV}_{1}$ and $\mathrm{FVC}^{24}$ and propranolol can reduce $\mathrm{FEV}_{1}$ and the bronchodilating effect of formoterol, thereby increasing airway hyperresponsiveness. ${ }^{25}$ All of these changes would cause detrimental effects in patients with COPD. Based on the current evidence, these two agents should not be prescribed to patients with COPD.
The major strength of this study is that it is a nationwide population-based cross-sectional study including almost all patients with COPD in Taiwan. In addition, to improve the accuracy of the diagnosis of COPD, only patients who received pulmonary function tests within 1 year of receiving a diagnosis of COPD were enrolled. Finally, we used GAMs to study the relationships between the mean daily dose of beta-blockers and the occurrence of severe exacerbations. By using GAMs, we could calculate the duration that the patients actually used beta-blockers during the follow-up period instead of conventional methods, which may overestimate the duration of taking medication, and therefore, we could accurately evaluate the impact of the accumulated dosage of beta-blockers that the patients really took. Therefore, our results should be representative of the status of patients with COPD in Taiwan who are treated with beta-blockers.

There are also several limitations to this study. First, we did not have detailed data on pulmonary function test results or quality of life assessments. Therefore, we could not evaluate the severity of COPD or determine whether every patient received appropriate COPD treatment according to 
the recommended guidelines. However, we only enrolled patients with COPD who received inhaled corticosteroids in our analysis, and this specific group had severe or very severe COPD. Second, we did not exclude the patients with concurrent asthma, who tend to not tolerate beta-blockers as COPD patients. Finally, this study was not a randomized controlled study. Nonetheless, our findings are derived from real-world data and are more likely to be reflective of common clinical practice.

\section{Conclusion}

Selective beta-blockers can be cautiously prescribed for patients with COPD and CVD; however, nonselective betablockers should not be prescribed for patients with COPD. Betaxolol may be the preferred choice of suitable selective beta-blocker for patients with COPD, however, labetalol and propranolol should be avoided for patients with COPD.

\section{Acknowledgments}

Taiwan Clinical Trial Consortium for Respiratory Diseases (TCORE) includes Chong-Jen Yu, MD, PhD (National Taiwan University Hospital [NTUH], Director of Coordinating Center and Core Principal Investigator [PI] of Committee); Hao-Chien Wang, MD, PhD (NTUH, PI of Committee); Diahn-Warng Perng, MD, PhD (Taipei Veterans General Hospital, PI of Committee); Shih-Lung Cheng, MD, PhD (Far Eastern Memorial Hospital, PI of Committee); JengYuan Hsu, MD, PhD (Taichung Veterans General Hospital, PI of Committee); Wu-Huei Hsu, MD, PhD (China Medical University Hospital, PI of Committee); Ying-Huang Tsai, MD, PhD (Chang Gung Memorial Hospital, Chiayi, PI of Committee); Tzuen-Ren Hsiue, MD, PhD (National Cheng Kung University Hospital, PI of Committee); Meng-Chih Lin, MD, PhD (Chang Gung Memorial Hospital, Kaohsiung, PI of Committee); Hen-I Lin, MD (Cardinal Tien Hospital and School of Medicine, PI of Committee); Cheng-Yi Wang, MD, PhD (Cardinal Tien Hospital and School of Medicine, PI of Committee); Yeun-Chung Chang, MD, PhD (NTUH, PI of Committee); Ueng-Cheng Yang, PhD (National YangMing University, PI of Committee); Chung-Ming Chen, PhD (NTU, PI of Committee); Cing-Syong Lin, MD, PhD (Changhua Christian Hospital, PI of Committee); Likwang Chen, PhD (NHRI, PI of Committee); Yu-Feng Wei, MD (E-Da Hospital, PI of Committee); Inn-Wen Chong, MD (Kaohsiung Medical University Chung-Ho Memorial Hospital, PI of Committee); and Chung-Yu Chen (NTUH, Yun-Lin, PI of Committee). This study was supported by grants from the National Science Council (NSC 104-2314-B002-185-MY2, 101-2325-B-002-064, 102-2325-B-002-087,
103-2325-B-002-027, 104-2325-B-002-035, 105-2325-B002-030, 104-2314-B-567-002, and 105-2314-B-567-001), Cardinal Tien Hospital and School of Medicine (FU10007, CTH-102-1-2B12, and CTH-103-1-2B02), and NHRI (intramural funding).

\section{Disclosure}

The authors report no conflicts of interest in this work.

\section{References}

1. Soriano JB, Visick GT, Muellerova H, Payvandi N, Hansell AL. Patterns of comorbidities in newly diagnosed COPD and asthma in primary care. Chest. 2005;128(4):2099-2107.

2. Fabbri LM, Luppi F, Beghé B, Rabe KF. Complex chronic comorbidities of COPD. Eur Respir J. 2008;31(1):204.

3. García-Olmos L, Alberquilla Á, Ayala V, et al. Comorbidity in patients with chronic obstructive pulmonary disease in family practice: a cross sectional study. BMC Fam Pract. 2013;14:11.

4. Feary JR, Rodrigues LC, Smith CJ, Hubbard RB, Gibson JE. Prevalence of major comorbidities in subjects with COPD and incidence of myocardial infarction and stroke: a comprehensive analysis using data from primary care. Thorax. 2010;65(11):956-962.

5. Gottlieb SS, McCarter RJ, Vogel RA. Effect of beta-blockade on mortality among high-risk and low-risk patients after myocardial infarction. N Engl J Med. 1998;339(8):489-497.

6. Chen J, Radford MJ, Wang Y, Marciniak TA, Krumholz HM. Effectiveness of beta-blocker therapy after acute myocardial infarction in elderly patients with chronic obstructive pulmonary disease or asthma. J Am Coll Cardiol. 2001;37(7):1950-1956.

7. Smith SC, Blair SN, Bonow RO, et al. AHA/ACC guidelines for preventing heart attack and death in patients with atherosclerotic cardiovascular disease: 2001 update a statement for healthcare professionals from the American Heart Association and the American College of Cardiology. Circulation. 2001;104:1577-1579.

8. Smith SC, Allen J, Blair SN, et al. AHA/ACC guidelines for secondary prevention for patients with coronary and other atherosclerotic vascular disease: 2006 update endorsed by the national heart, lung, and blood institute. J Am Coll Cardiol. 2006;47:2130-2139.

9. Doughty RN, Rodgers A, Sharpe N, MacMahon S. Effects of betablocker therapy on mortality in patients with heart failure. A systematic overview of randomized controlled trials. Eur Heart J. 1997;18(4): 560-565.

10. Hurst JR, Vestbo J, Anzueto A, et al. Evaluation of COPD Longitudinally to Identify Predictive Surrogate Endpoints (ECLIPSE) Investigators. Susceptibility to exacerbation in chronic obstructive pulmonary disease. N Engl J Med. 2010;363(12):1128-1138.

11. Salpeter SR, Ormiston TM, Salpeter EE. Cardioselective beta-blockers in patients with reactive airway disease: a meta-analysis. Ann Intern Med. 2002;137(9):715-725.

12. Dransfield MT, Rowe SM, Johnson JE, Bailey WC, Gerald LB. Use of beta blockers and the risk of death in hospitalised patients with acute exacerbations of COPD. Thorax. 2008;63(4):301-305.

13. Au DH, Bryson CL, Fan VS, et al. Beta-blockers as single-agent therapy for hypertension and the risk of mortality among patients with chronic obstructive pulmonary disease. Am J Med. 2004;117(12):925-931.

14. Short PM, Lipworth SI, Elder DH, Schembri S, Lipworth BJ. Effect of beta blockers in treatment of chronic obstructive pulmonary disease: a retrospective cohort study. BMJ. 2011;342:d2549.

15. Rutten FH, Zuithoff NP, Hak E, Grobbee DE, Hoes AW. Betablockers may reduce mortality and risk of exacerbations in patients with chronic obstructive pulmonary disease. Arch Intern Med. 2010; 170(10):880-887.

16. Du Q, Sun Y, Ding N, Lu L, Chen Y. Beta-blockers reduced the risk of mortality and exacerbation in patients with COPD: a meta-analysis of observational studies. PLoS One. 2014;9(11):e113048. 
17. Vestbo J, Hurd SS, Agusti AG, et al. Global strategy for the diagnosis, management, and prevention of chronic obstructive pulmonary disease: GOLD executive summary. Am J Respir Crit Care Med. 2013;187(4):347-365.

18. Wang CY, Lai CC, Yang WC, et al. The association between inhaled corticosteroid and pneumonia in COPD patients: the improvement of patients' life quality with COPD in Taiwan (IMPACT) study. Int $J$ Chron Obstruct Pulmon Dis. 2016;11:2775-2783.

19. Matthews R, Brill I. SAS ${ }^{\circledR}$ programs to select controls for matched case-control studies. SAS User Group Proceedings. Birmingham, AL: University of Alabama at Birmingham; 2005;30:152-230.

20. Ni Y, Shi G, Wan H. Use of cardioselective beta-blockers in patients with chronic obstructive pulmonary disease: a meta-analysis of randomized, placebo-controlled, blinded trials. J Int Med Res. 2012;40(6): 2051-2065.
21. Salpeter S, Ormiston T, Salpeter E. Cardioselective beta-blockers for chronic obstructive pulmonary disease. Cochrane Database Syst Rev. 2005;4:CD003566.

22. Miki A, Tanaka Y, Ohtani H, Sawada Y. Betaxolol-induced deterioration of asthma and a pharmacodynamic analysis based on beta-receptor occupancy. Int J Clin Pharmacol Ther. 2003;41(8):358-364.

23. Ofner S, Smith TJ. Betaxolol in chronic obstructive pulmonary disease. J Ocul Pharmacol. 1987;3(2):171-176.

24. Anavekar SN, Barter C, Adam WR, Doyle AE. A double-blind comparison of verapamil and labetalol in hypertensive patients with coexisting chronic obstructive airways disease. J Cardiovasc Pharmacol. 1982;4(supp1 3):S374-S377.

25. van der Woude HJ, Zaagsma J, Postma DS, Winter TH, van Hulst M, Aalbers R. Detrimental effects of beta-blockers in COPD: a concern for nonselective beta-blockers. Chest. 2005;127(3):818-824. 


\section{Supplementary materials}

673,676 COPD patients from January 1, 1998 to December 31, 2010

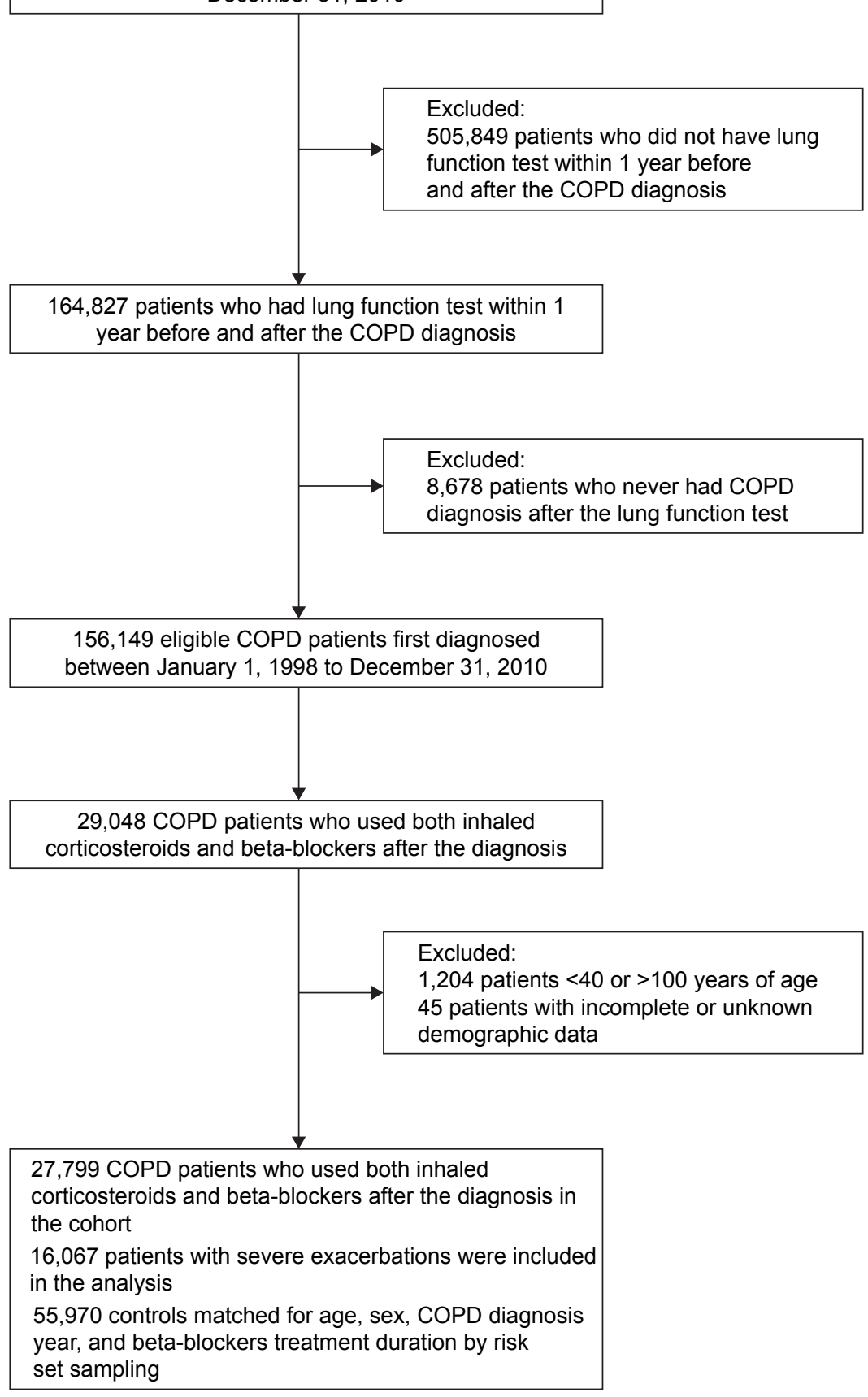

Figure SI Study flow chart. 
A

Cubic splines fit by conditional logistic regression

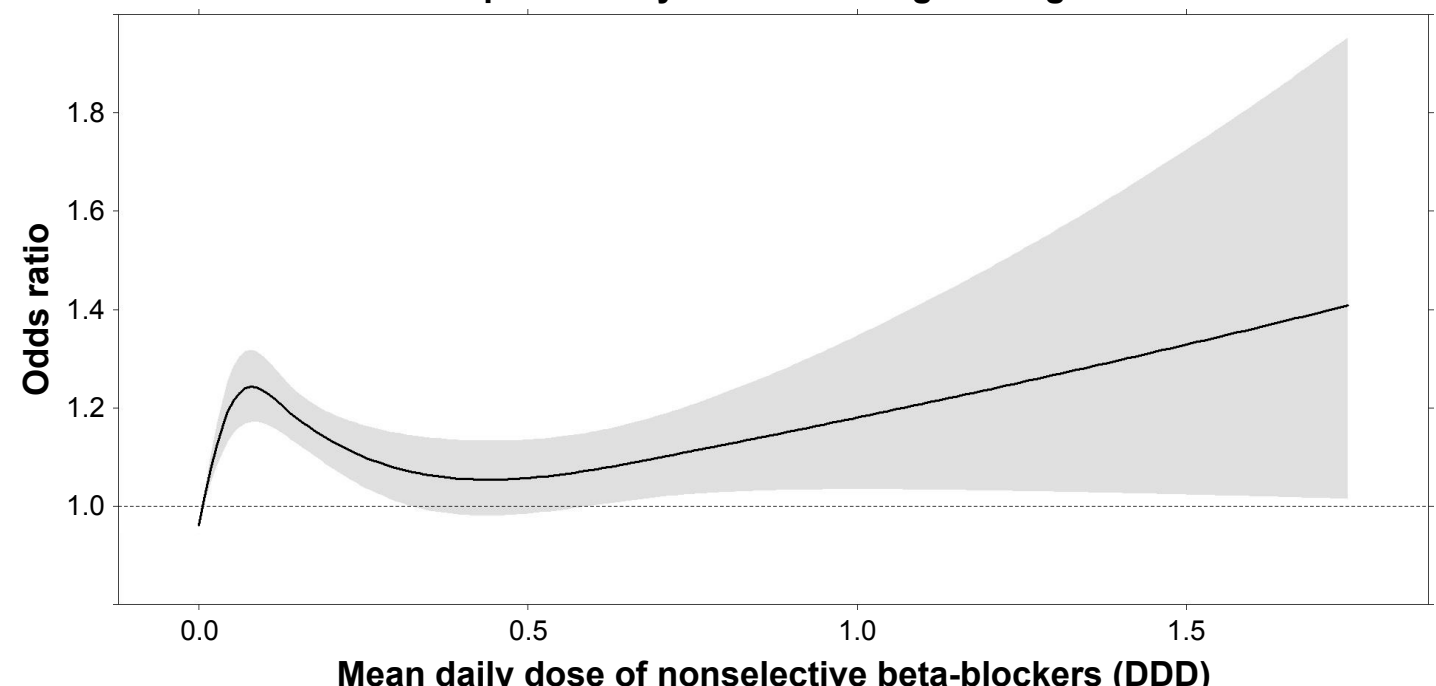

Mean daily dose of nonselective beta-blockers (DDD)

B Cubic splines fit by conditional logistic regression

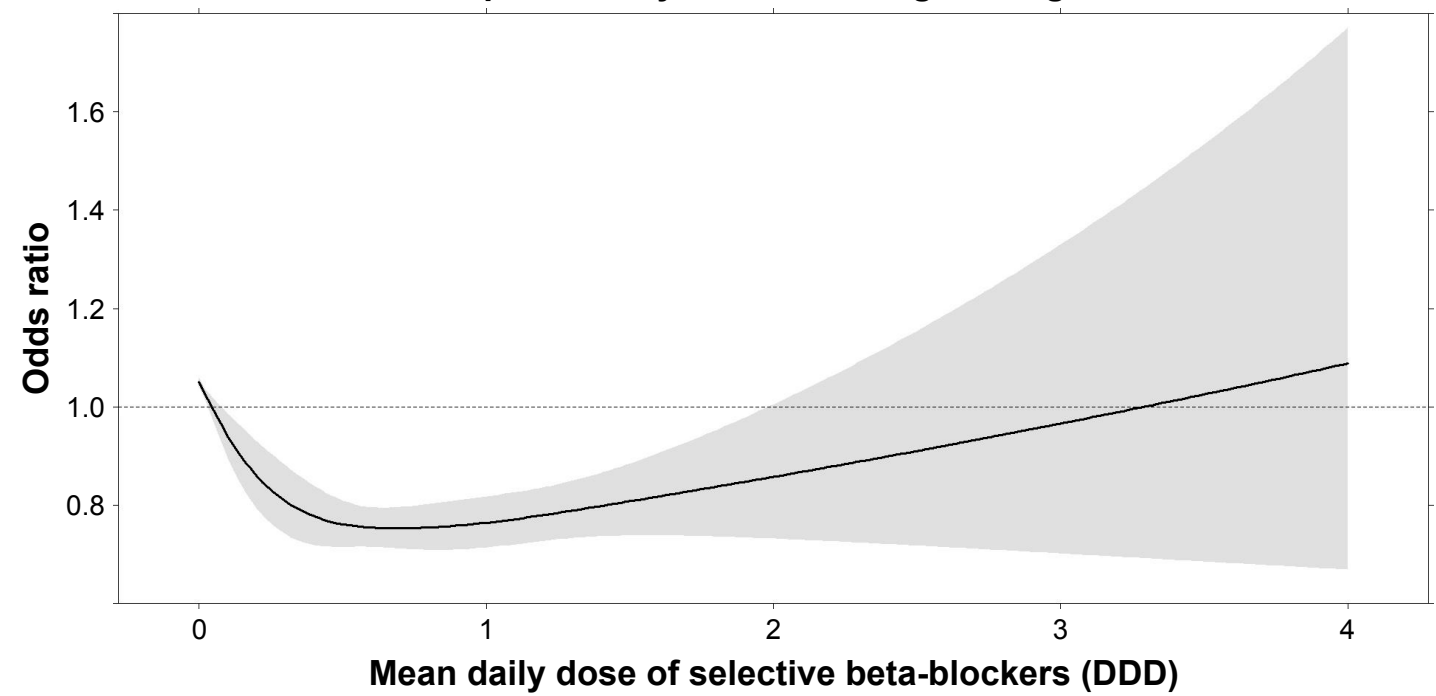

Figure S2 Occurrence of severe acute exacerbation vs mean daily dose (DDD) of (A) nonselective and (B) selective beta-blockers. Abbreviation: DDD, defined daily dose. 
A Cubic splines fit by conditional logistic regression

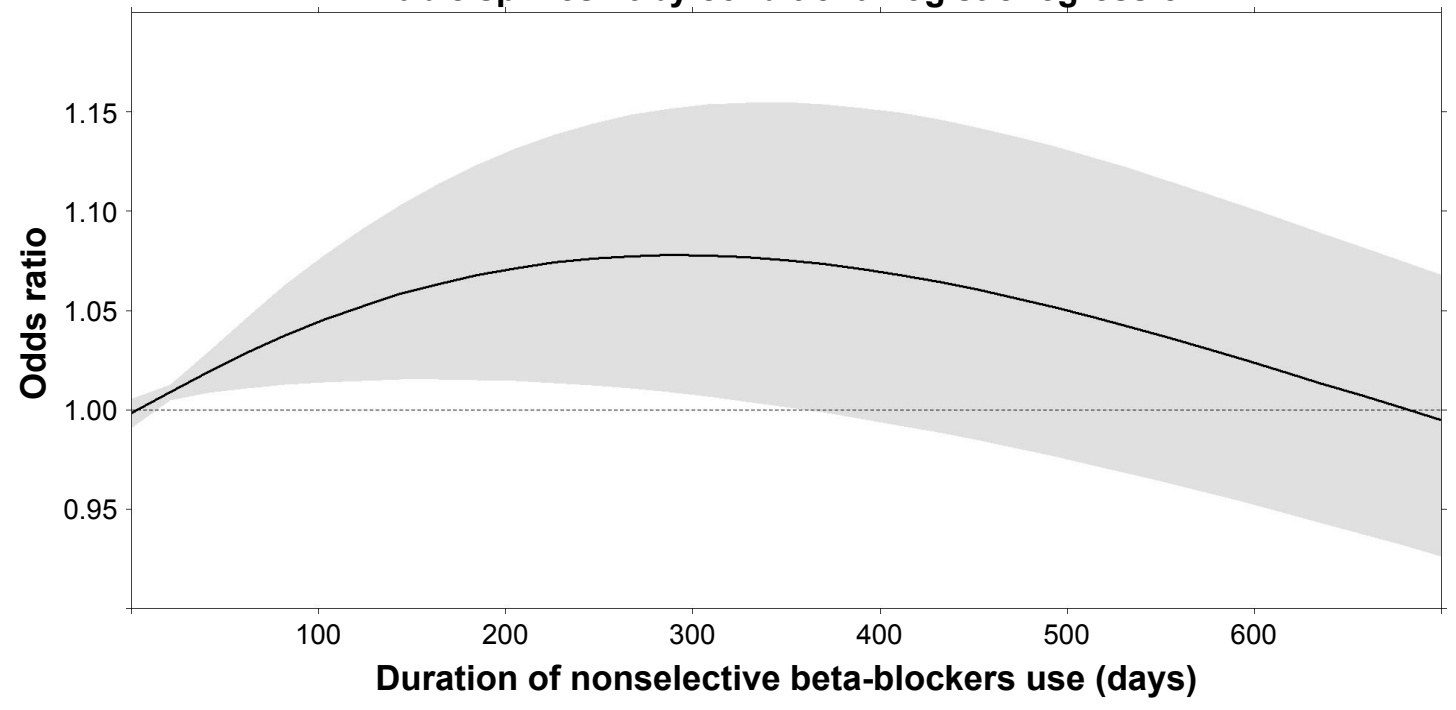

B Cubic splines fit by conditional logistic regression

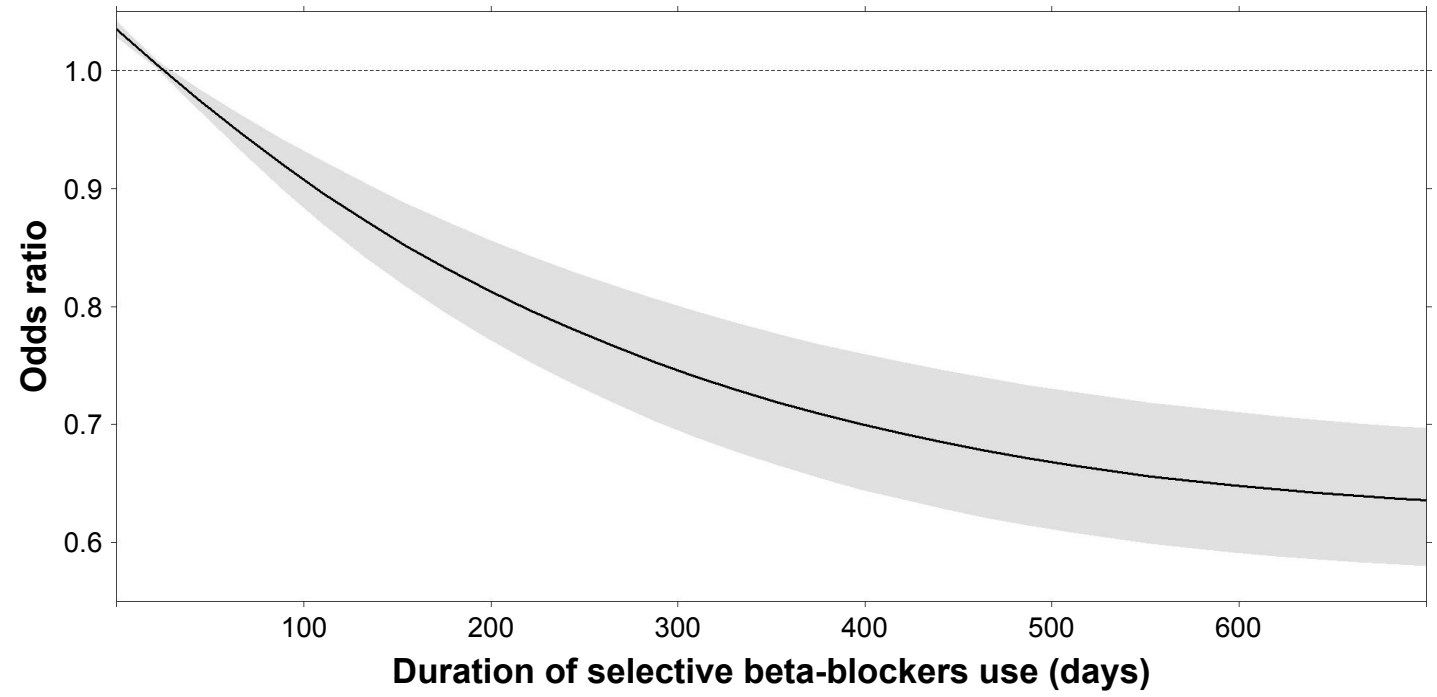

Figure S3 Occurrence of severe acute exacerbation vs duration (days) of (A) nonselective and (B) selective beta-blockers.

\section{Publish your work in this journal}

The International Journal of COPD is an international, peer-reviewed journal of therapeutics and pharmacology focusing on concise rapid reporting of clinical studies and reviews in COPD. Special focus is given to the pathophysiological processes underlying the disease, intervention programs, patient focused education, and self management protocols.
Dovepress

This journal is indexed on PubMed Central, MedLine and CAS. The manuscript management system is completely online and includes a very quick and fair peer-review system, which is all easy to use. Visit http://www.dovepress.com/testimonials.php to read real quotes from published authors. 